\title{
Leitura do livro de Mario Perniola, 0 Sex Appeal do Inorgânico (Coimbra, Ariadne Editora: 2004)
}

José Pinheiro Neves"

Luís Tavares"*

Mario Perniola, professor de estética na Universidade de Roma, inspira-se numa frase de Walter Benjamin acerca do sex appeal do inorgânico (p. 6), para retomar, de uma forma inovadora, alguns dos seus livros anteriores. Partindo da filosofia grega antiga, em torno de uma outra forma de sentir não eufórica, desloca-se pelo pensamento acerca da "coisa" em Kant (a coisa em si), Heidegger (o questionamento da coisa) e Lacan (a coisa freudiana), passando também pela noção de "sentindo impessoal" (feeling) a partir de Kant (o sentimento), de Hegel (pathos) e de uma estética da empatia em que não existe um sujeito centrado. «Sou uma coisa que pensa» - é o ponto central da argumentação de Perniola.

Perniola desenvolve um trabalho que já vem de longe. Tal como ele afirma, «nos meus livros, investiguei as origens do sentir impessoal nas possessões da religião grega antiga e dos cultos das religiões afro-brasileiras (candomblé e xangó), na filosofia helenística, no neo-estoicismo da idade barroca, na cultura e no pensamento austríaco entre os séculos XIX e XX, bem como em tantos fenómenos da experiência contemporânea (das sensologias de massa às toxicomanias, das tecnologias virtuais às psicoses, da arquitectura desconstrutiva à arte pós-humana, das perversões sexuais às doenças do sistema imunitário, dos desportos radicais a alguns géneros da indústria cultural como o horror, a ficção científica, o rock)» (Perniola, 2006: 4). Mas, sendo esta a sua força e originalidade, não se deixa fechar por uma lógica intelectual. Não é apenas o pensar que é necessário descentrar do nosso "eu" ainda preso na armadilha cartesiana e "subjectiva". É muito mais do que isso. É também o seguir um apelo antigo. «Uma experiência neutra e impessoal.»

De uma forma original, o livro não se deixa fechar num debate árido filosófico mas é constantemente atravessado por descrições densas desta forma de sentir na arte e na vida dita "sexual": passar de uma forma obcecada pelo "orgasmo" para uma lógica mais "neutra e impessoal". Estamos definitivamente perante um livro que convoca outros leitores, um livro que permite uma consciência talvez mais clara das formas de sensibilidade emergentes.

Desenvolverei, em seguida, algumas considerações em torno da noção de inorgânico, que me parece ser central nesta sua obra. O que há, neste inorgânico, de sex appeal? Estará o autor a falar de cibersexo ou do discurso do pós-humano? Não é bem

\footnotetext{
* Centro de Estudos Comunicação e Sociedade, Universidade do Minho.jpneves@ics.uminho.pt
}

** Licenciado em Filosofia pela Universidade Nova de Lisboa. 
isso, ainda que esses temas estejam presentes. A ideia de Perniola é outra, simples e surpreendente.

Perniola parte de uma observação de Walter Benjamin. Segundo este autor, a moda é, de uma forma crua, considerada o "sex appeal do inorgânico". ${ }^{1}$ A moda, ou seja, as mulheres com os seus vestidos, que ele observa nas ruas de Paris, representam o triunfo da forma sendo o corpo, aparentemente, um resto: estamos assim perante uma mescla entre coisas inorgânicas e orgânicas. Por isso, há um sex appeal que vem de algo que já não é apenas o corpo mas esta conjunção, este cyborg emergente.

Com a expansão destas mesclas por todo o lado com as novas tecnologias da informação e da comunicação, a intuição de Benjamin ganha uma outra acutilância. Não existindo um centro definido de subjectividade, um centro do sentir, abre-se esta possibilidade: somos nós também uma parte de inorgânico. «O cyborg filosófico-sexual apresenta uma sociabilidade intrínseca, que todavia não depende da intersubjectividade, mas de uma relação de interfaces, que interage não entre dois sujeitos mas entre duas quase coisas» (p. 37). Um cyborg que assume a ideia de que os nosso interfaces quotidianos, nas nossas carnes, também são eles interfaces de misturas de orgânico/ inorgânico. Ou melhor, a fronteira em que assentamos a nossa certeza cartesiana está ela própria baseada em pés de barro como mostram igualmente os trabalhos recentes do neurologista António Damásio. Um pé de barro é uma expressão curiosa e que se aplica muito bem a esta tentativa de Perniola.

De facto, a nossa experiência de cyborg não é estranha ao ser humano. Já antes, como vimos atrás, Walter Benjamin tinha sublinhado que a experiência da modernidade apontava para essa cada vez maior reificação: estamos imersos em mesclas de cyborg. Estamos todos cada vez mais mergulhados numa «mescla entre a dimensão humana e a dimensão "coisal", através da qual, por um lado, a sensibilidade humana se reifica e, por outro, as coisas parecem dotadas de uma sensibilidade própria. [...] Com efeito, o inorgânico não é unicamente o mineral, mas também o cadavérico, o mumificado, o tecnológico, o químico, o mercantil, e o fetiche: também este se materializa, se transforma em algo de abstracto e de incorpóreo, sem por isso se transformar em qualquer coisa de imaginário ou irreal; assim, por detrás de todas estas configurações do inorgânico opera o paradigma daquilo que é maximamente real e efectivo, e que é o dinheiro [...] envolvendo, com laços inextricáveis, sexualidade, filosofia e economia» (Perniola, 1998: 175).

Nesse sentido, o que nos diz Perniola assume um outro estatuto que não se confunde com os discursos eufóricos do pós-humano: «na medida em que o utente é transformado num cibernauta que navega na realidade virtual, ele aprende a perceber o próprio corpo real como uma coisa senciente, não essencialmente diversa das paisagens quase sencientes das arquitecturas electrónicas» (p. 83). Não há dicotomia total e clara entre o homem (centro da subjectividade) e as arquitecturas electrónicas

${ }^{1}$ Benjamin, Walter, 1982, Das Passagen-Werk, Frankfurt a. M., Suhrkamp; trad. it., 1986, Parigi, Capitale del XIX secolo. I passages di Parigi, Torino, Einaudi.1982, p. 124 citado no livro de Perniola. 
normalmente apresentadas como desumanas e ameaçadoras da "humanidade" ou, no seu oposto pós-humano, como motivo de uma euforia. O corpo real, sentido pelo cibernauta, é também já um senciente (feeling) que não é centrado na ideia da unidade do eu. Já é outra coisa: são feelings em que o senciente (feeling) de um e do outro lado não são essencialmente diferentes. Desta forma, até mesmo a noção de fronteira entre orgânico e inorgânico é abalada ou, pelo menos, repensada.

O mesmo afirma Paul Virilio quando nos desmonta a noção de representação do real na fotografia. No fundo, o que denuncia em relação às imagens das próteses (fotografias, televisão, etc.) já existe potencialmente em todo o acto técnico tal como nos é revelado por Perniola. A descolagem retiniana provocada pela prótese da máquina fotográfica, na medida em que perde o referencial da relação na duração temporal e com a sua topografia, já existe em toda a técnica (Virilio, 1988: 17-20). Por isso, o carácter inorgânico da visão externa é internalizado. Como diz Perniola, alargando a intuição de Virilio, não é apenas o olhar mas o próprio sentir, o feeling inorgânico que molda o nosso olhar.

Talvez haja algo de profunda metanóia neste livro de Perniola porque é para um autêntico processo de terapia, de descentramento que o autor nos convida. «A experiência que os meus livros propõem é um sentir empurrado para fora, feito sair, expulso do sujeito posto num âmbito neutro e impessoal» (Perniola, 2006: 4).

Perniola não nos deixa indiferentes. Quando ele nos descreve um sentir-sentindo que nos aproxima do inorgânico, alguns de nós somos tentados a reagir de uma forma "humanista" perante a redução do ser humano a uma "coisa". Esta reaç̧ão talvez se aproxime do sentimento experimentado por alguns leitores de Nietzsche, em finais do século XIX, quando este esgrimia em torno da morte do eu cartesiano, a irrupção de uma outra forma de ser homem. Também Perniola possui essa arte que Richard Rorty classifica de ironista, aquela que nos desinstala, que nos abala por dentro ao constituir-se como "o diferente". A nossa primeira reaç̧ão vai, por isso, no sentido do que Arendt designava de reacção ao estranho como símbolo assustador. "O "estranho" é um símbolo assustador pelo facto da diferença em si, da individualidade em si, e evoca essa esfera onde o homem não pode actuar nem mudar e na qual tem, portanto, uma definida tendência para destruir»(Arendt, 1978: 387). No entanto, se ultrapassarmos essa reacção baseada no conforto da representação e da instrumentalidade da técnica, talvez uma outra visão e um outro sentindo do mundo nasça que vá mais longe do que a crise do "eu" cartesiano.

Que ensinamentos práticos a partir deste livro?

Fundamentalmente a ideia de que uma nova forma de animalidade/humanidade está a disseminar-se. Desta forma, uma questão surge: como criar uma outra forma que evite esta "experiência cada vez mais empobrecida do mundo", como dizia Walter Benjamin? Apenas criando uma outra forma de estar com os objectos técnicos emergentes que nos leve a proteger o que é essencial. Como diz Teresa Cruz, devemos criar «uma nova animalidade, talvez, ou, pelo menos, num certo sentido, uma nova ferocidade, que implica sabermos, atender e proteger de facto, na urgência e no despro- 
vimento, o que é verdadeiramente essencial. De novo, como primordialmente acontecia no seio da natureza, o humano parece ser uma frágil condição, sem verdadeiras garantias. Neste sentido, a nova cosmogonia horizontal em que estamos lançados só encontra de facto paralelo nessa situação absolutamente primeva da história humana, quando não estava ainda garantida a supremacia do homem sobre os outros seres, nem inventada a supremacia de nenhum Deus sobre os homens. É neste sentido que uma tal condição merece, sem dúvida, o nome de uma nova natureza. Das novas coisas, não tenhamos a ilusão de serem meros objectos, sobre os quais temos ainda a confortável distância da representação ou da instrumentalidade» (Cruz, 2002).

Esta nova cosmogonia horizontal, não só aprofunda a crise já detectada por Nietzsche, mas também revela uma outra forma de nos relacionarmos com os objectos técnicos, uma consciência da nossa condição de cyborg.

\section{Referências bibliográficas}

Arendt, Hannah (1978), O Sistema Totalitário, Lisboa: Publicações Dom Quixote.

Cruz, Maria Teresa (2002), "O artificial ou a era do design total”, in Revista On Line de Arte, Cultura e Tecnologia, n. ${ }^{\circ}$ 7, 2002, Protocolo disponível: http://www.intearct.com.pt [15 de Setembro de 2006]

Perniola, Mario (2006), "Filosofia e globalização", in XX Encontro de Filosofia. A Filosofia na Era da Globalização, Coimbra: Associação de Professores de Filosofia.

Perniola, Mario (1998), A Estética do Século XX, Lisboa: Editorial Estampa.

Virilio, Paul (1988), La Machine de vision, Paris: Éditions Galilée. 